\title{
Melanopsin and Rod-Cone Photoreceptors Play Different Roles in Mediating Pupillary Light Responses during Exposure to Continuous Light in Humans
}

\author{
Joshua J. Gooley, ${ }^{1,2,3}$ Ivan Ho Mien, ${ }^{4}$ Melissa A. St. Hilaire, ${ }^{2,3}$ Sing-Chen Yeo, ${ }^{5}$ Eric Chern-Pin Chua, ${ }^{1}$ Eliza van Reen, ${ }^{2,3}$ \\ Catherine J. Hanley, ${ }^{2}$ Joseph T. Hull, ${ }^{2,3}$ Charles A. Czeisler, ${ }^{2,3}$ and Steven W. Lockley ${ }^{2,3}$ \\ ${ }^{1}$ Program in Neuroscience and Behavioral Disorders, Duke-National University of Singapore Graduate Medical School Singapore, Singapore 169857, \\ ${ }^{2}$ Division of Sleep Medicine, Department of Medicine, Brigham and Women's Hospital, and ${ }^{3}$ Division of Sleep Medicine, Department of Medicine, Harvard \\ Medical School, Boston, Massachusetts 02115, ${ }^{4}$ Graduate School for Integrative Sciences and Engineering, National University of Singapore, Singapore \\ 117456, and ${ }^{5}$ National Neuroscience Institute, Singapore 308433
}

In mammals, the pupillary light reflex is mediated by intrinsically photosensitive melanopsin-containing retinal ganglion cells that also receive input from rod-cone photoreceptors. To assess the relative contribution of melanopsin and rod-cone photoreceptors to the pupillary light reflex in humans, we compared pupillary light responses in normally sighted individuals $(n=24)$ with a blind individual lacking rod-cone function. Here, we show that visual photoreceptors are required for normal pupillary responses to continuous light exposure at low irradiance levels, and for sustained pupillary constriction during exposure to light in the long-wavelength portion of the visual spectrum. In the absence of rod-cone function, pupillomotor responses are slow and sustained, and cannot track intermittent light stimuli, suggesting that rods/cones are required for encoding fast modulations in light intensity. In sighted individuals, pupillary constriction decreased monotonically for at least $30 \mathrm{~min}$ during exposure to continuous low-irradiance light, indicating that steady-state pupillary responses are an order of magnitude slower than previously reported. Exposure to low-irradiance intermittent green light (543 $\mathrm{nm} ; 0.1-4 \mathrm{~Hz}$ ) for $30 \mathrm{~min}$, which was given to activate cone photoreceptors repeatedly, elicited sustained pupillary constriction responses that were more than twice as great compared with exposure to continuous green light. Our findings demonstrate nonredundant roles for rod-cone photoreceptors and melanopsin in mediating pupillary responses to continuous light. Moreover, our results suggest that it might be possible to enhance nonvisual light responses to low-irradiance exposures by using intermittent light to activate cone photoreceptors repeatedly in humans.

\section{Introduction}

The pupillary light reflex (PLR) regulates the amount of light that reaches the retina. In doing so, the PLR optimizes visual acuity over a wide range of illuminance levels (Campbell and Gregory, 1960) and protects the retina from the potentially damaging effects of exposure to bright light. The PLR is mediated by melanopsin-containing retinal ganglion cells that project directly

Received March 17, 2012; revised June 29, 2012; accepted Aug. 8, 2012.

Author contributions: J.J.G., C.A.C., and S.W.L. designed research; J.J.G., I.H.M., M.A.S.H., S.-C.Y., E.C..P.C., E.v.R., C.J.H., and J.T.H. performed research; J.J.G., I.H.M., S.-C.Y., and E.C.-P.C. analyzed data; J.J.G., C.A.C., and S.W.L. wrote the paper.

This work was supported by the Duke-National University of Singapore (NUS) Signature Research Program funded by the Agency for Science, Technology and Research, Singapore, and the Ministry of Health, Singapore; National Medical Research Council, Singapore, under NIG09may007 (J.J.G.); NIH Grants T32-HL07901 (J.J.G., M.A.S.H.), MH45130 (C.A.C., S.W.L.), and AT002129 (S.W.L.); Brigham and Women's Hospital (BWH) General Clinical Research Center, Grant M01 RR02635; Harvard Clinical and Translational Science Center, Grant 1 UL1 RR025758, from the National Center for Research Resources. S.W.L. and C.A.C. were supported in part by the National Space Biomedical Research Institute through NASA NCC 9-58. We thank research volunteers, participant recruiters, and research and medical staff at Duke-NUS Graduate Medical School and the Division of Sleep Medicine, BWH.

The authors declare no competing financial interests.

Correspondence should be addressed to Dr. Joshua J. Gooley, Duke-National University of Singapore Graduate Medical School Singapore, 8 College Road, Singapore 169857. E-mail: gmsjjg@nus.edu.sg.

DOI:10.1523/JNEUROSCI.1321-12.2012

Copyright $\odot 2012$ the authors $\quad 0270-6474 / 12 / 3214242-12 \$ 15.00 / 0$ to the olivary pretectal nucleus (Hattar et al., 2002; Gooley et al., 2003). Melanopsin cells are intrinsically photosensitive and respond most strongly to short-wavelength light in the blue portion of the visual spectrum (Berson et al., 2002; Dacey et al., 2005). Rod-cone photoreceptors also provide input to melanopsin cells (Belenky et al., 2003; Wong et al., 2007), but melanopsin cells are not required for pattern-forming vision (Güler et al., 2008). In contrast, the PLR and other nonvisual light responses are abolished if rod-cone and melanopsin signaling pathways are disrupted simultaneously (Hattar et al., 2003; Panda et al., 2003), or if melanopsin cells are selectively killed (Güler et al., 2008).

In humans, rods and cones are capable of driving the initial rapid constriction of the pupils in response to light (Alpern and Campbell, 1962), whereas the PLR is most sensitive to shortwavelength blue light during exposure to continuous light (Bouma, 1962; Alexandridis and Koeppe, 1969; Mure et al., 2009; McDougal and Gamlin, 2010), even in the absence of rod and cone function (Zaidi et al., 2007), suggesting a primary role for melanopsin photopigment. For light intensities below the threshold of activation for melanopsin cells, spectral responses of the PLR during exposure to continuous light are consistent with a role for rods, with little or no contribution from cones (McDou- 
gal and Gamlin, 2010). By comparison, attempts to isolate visual photoreceptor contributions to the PLR using the method of silent substitution have yielded contrasting results, with one study reporting a contribution from M- and L-cones (Tsujimura et al., 2010), and another reporting a possible contribution from rod photoreceptors (Viénot et al., 2010).

Melanopsin and rod-cone contributions to the PLR are difficult to assess in normally sighted humans due to overlap of spectral sensitivity for the various photoreceptor types. As demonstrated in macaques, which have trichromatic vision similar to humans, melanopsin-dependent pupillary responses can be examined in isolation when rod-cone signaling is disrupted (Gamlin et al., 2007). Hence, the role of melanopsin versus rod-cone photoreceptors in driving pupillary light responses could potentially be assessed in blind humans with complete loss of visual function, but with preservation of the retinal ganglion cell layer and melanopsin function (Czeisler et al., 1995; Klerman et al., 2002; Zaidi et al., 2007). To date, however, fewer than a dozen such patients have been identified worldwide. In the present study, we provide a detailed analysis of pupillary light responses in a patient with intact nonvisual responses to light (Zaidi et al., 2007), but without a functional outer retina. Here, the relative contribution of melanopsin and visual photoreceptors was assessed by comparing PLR responses in the totally visually blind patient with normally sighted individuals.

\section{Materials and Methods}

Participants. Healthy individuals ( $n=24 ; 12$ males and 12 females) and a blind male with intact circadian photoreception (Zaidi et al., 2007) were enrolled in a $3 \mathrm{~d}$ laboratory study. Normally sighted individuals ranged in age from 19 to 45 years $(19-24$ years, $n=17 ; 25-30$ years, $n=4 ;>30$ years, $n=3$ ), and the blind participant was 58 years of age at the time of study. Twelve sighted participants were studied at the Chronobiology and Sleep Laboratory (CSL), Duke-National University of Singapore Graduate Medical School Singapore (Duke-NUS GMS), including one person who returned to complete a second $3 \mathrm{~d}$ study. Twelve sighted participants and the blind individual were studied at the Intensive Physiologic Monitoring (IPM) Unit, Harvard Clinical and Translational Science Center, Brigham and Women's Hospital (BWH) (Boston, MA). In all participants, health was assessed by screening questionnaires and selfreported medical history. Individuals studied at BWH also had a physical examination to confirm normal health. Normal color vision was confirmed in all sighted participants by an ophthalmologic examination and/or the Ishihara test for color blindness. The blind individual was diagnosed with retinitis pigmentosa at 35 years of age. A fundoscopic examination confirmed atrophy of the retinal pigment epithelium, with thinning of retinal vessels and bone spicule pigmentation. Visual acuity tests indicated no light perception in either eye, and no visually evoked potentials were detected in multiple tests, consistent with total loss of rod-cone function and the patient's reported inability to see light. These findings were confirmed before and after the study by different ophthalmologists who examined the patient independently. As determined in a previous study, the blind individual was entrained and showed intact light-induced melatonin suppression in response to bright polychromatic white light or short-wavelength $460 \mathrm{~nm}$ light, indicating preservation of nonvisual light responses despite loss of rod-cone-based vision (Zaidi et al., 2007).

For at least 1 week before being admitted to the CSL or IPM Unit, participants were required to maintain a fixed sleep-wake cycle of their choice ( $8 \mathrm{~h}$ of sleep, $16 \mathrm{~h}$ of wake), which was verified by continuous actigraphy monitoring (Actiwatch-L; Mini Mitter). During prestudy screening, participants were asked to avoid caffeine, alcohol, and overthe-counter medications. In two participants, the laboratory study was ended early due to equipment failure, and one person withdrew from the study on day 2 due to difficulty tolerating the protocol. Informed consent was obtained from all participants, and research procedures were ap- proved by the SingHealth Centralized Institutional Review Board (Singapore) or the Partners Human Research Committee (Boston, MA). Research was compliant with the Health Insurance Portability and Accountability Act regulations and the Declaration of Helsinki.

General procedures. Participants lived individually for $3 \mathrm{~d}$ in a windowless environment without time cues and were scheduled to sleep and wake at their regular prestudy sleep-wake times. Beginning $\sim 3 \mathrm{~h}$ after wake time, participants were administered a series of light exposures between 10:00 A.M. and 7:00 P.M. in a room that was otherwise dark. Narrow-bandwidth light (half-peak bandwidth, $10 \mathrm{~nm}$ ) was generated by a xenon arc lamp and grating monochromator, and light exposures were administered using a modified Ganzfeld dome as previously described (Brainard et al., 2001; Gooley et al., 2010). Polychromatic white light exposures were delivered using ceiling-mounted or wall-mounted $4100 \mathrm{~K}$ fluorescent lamps (Philips Lighting). For light exposures given by liquid crystal display (LCD) monitor, participants were seated $48 \mathrm{~cm}$ away from a $54.6 \mathrm{~cm}$ monitor (Samsung SyncMaster P2250) with their head position fixed by a chin rest. Light levels were measured before and after each light exposure using an ILT1700 radiometer fitted with an SEL-033/F/W or SED-033/F/W detector (International Light Technologies). Spectral composition of light was determined with a PR-650 SpectraColorimeter (Photo Research) or ILT900 spectroradiometer (International Light Technologies). During breaks and free time, participants were exposed to $<5 \operatorname{lux}$ (Duke-NUS GMS) or $<3$ lux $(\mathrm{BWH})$ of ambient light provided by overhead light-emitting diode or fluorescent ceiling lamps.

Before each light exposure, participants were exposed to darkness for at least $6 \mathrm{~min}$ to allow cone photoreceptors time to dark adapt (Rushton, 1963). Light exposures ranged from 2 to 90 min depending on which experiment was being conducted (see below), and both eyes were exposed to full-field retinal illumination without use of a mydriatic agent. Pupil diameter was measured from the left eye at $120 \mathrm{~Hz}$ using a headmounted infrared pupillography system (ISCAN). Participants were instructed to avoid photophobic behavior (e.g., closing or squinting of the eyes), which was enforced by research staff who monitored a live video of the pupil in the control room.

To determine percentage pupillary constriction, pupil diameter during each light exposure $\left(d_{\mathrm{LE}}\right)$ was compared with pupil diameter during the preceding dark adaptation period $\left(d_{\max }\right)$. The difference in pupil diameter $\left(d_{\max }-d_{\mathrm{LE}}\right)$ was expressed relative to each individual's maximum difference in pupil diameter for a bright white light stimulus $(\sim 2500$ lux $)$ versus exposure to darkness $\left(d_{\max }-d_{\min }\right)$ as follows:

$$
\% \text { Constriction }=100 \times \frac{d_{\max }-d_{\mathrm{LE}}}{d_{\max }-d_{\min }} .
$$

Experiment 1: irradiance-dependent responses. Four sighted participants (A-D) were exposed to 2-10 min of narrow-bandwidth 480 or $555 \mathrm{~nm}$ light across a $5 \log$ range of irradiances $\left(9-14 \log\right.$ photons $\left.\mathrm{cm}^{-2} \mathrm{~s}^{-1}\right)$, with order of wavelength and irradiance randomized. Percentage pupillary constriction was analyzed during the first $2 \mathrm{~min}$ of light exposure. We excluded participant $C$ from our analysis because her pupils showed strong and sustained constriction at all irradiances tested. In the remaining participants $(n=3)$, percentage pupillary constriction was averaged between participants at each irradiance level to generate irradiance-response curves for 480 and $555 \mathrm{~nm}$ light. In addition, the blind participant received $114 \mathrm{~min}$ exposures to $480 \mathrm{~nm}$ light across a 2.5 log range of irradiances $\left(11-13.5 \log\right.$ photons $\left.\mathrm{cm}^{-2} \mathrm{~s}^{-1}\right)$. We did not attempt to construct an irradiance-response curve to $555 \mathrm{~nm}$ light in the blind individual, as pupillary responses were weak even at high irradiances.

Irradiance-response curves were fit with a sigmoidal four-parameter logistic regression model as follows:

$$
y=y_{0}+\frac{a}{1+\left(\frac{x}{x_{0}}\right)^{b}} .
$$

Maximum percentage pupillary constriction was set at 100\%, and minimum constriction was constrained to $0 \%$ in the dark-adapted state; hence, $a=d_{\max }-d_{\min }$. The irradiance that elicited a half-maximal 
response $\left(x_{0}\right.$; the $\mathrm{ED}_{50}$ value $)$ and the slope parameter $(b)$ were estimated using the Levenberg-Marquardt method for nonlinear least-squares minimization (SigmaPlot 11; Systat Software). Residuals were normally distributed, as determined by the Shapiro-Wilk test for normality ( $W>$ 0.95 and $p>0.45$ ).

The extra sum-of-squares $F$ test was used to compare irradiance-response curves in sighted participants versus the blind individual (Motulsky and Christopoulos, 2008). To test whether the $\log \mathrm{ED}_{50}$ or slope parameter differed significantly, we performed a global curve fit in which the best-fit value for each parameter was shared for dose-response curves in normally sighted individuals and the blind participant (SigmaPlot 11). The $F$ test was used to determine whether the model with unshared log $\mathrm{ED}_{50}$ or slope resulted in a significant improvement in the difference in sum of squares, compared with the model in which irradiance-response curve parameters were shared (Gooley et al., 2010). We used the same $F$ test to compare dose-response curves to 480 versus $555 \mathrm{~nm}$ light in sighted individuals.

In the blind participant and in a separate group of sighted participants $(n=4$; E-H), we examined pupillary constriction responses to 90 or 2500 lux of polychromatic white light. Participants were exposed to 10 min of darkness, followed by $10 \mathrm{~min}$ of exposure to white light. The light was then turned off for an additional $10 \mathrm{~min}$ so that we could examine the time course of pupillary redilation in darkness.

Experiment 2: wavelength-dependent responses. Sighted participants $(n=5 ; \mathrm{D}-\mathrm{H})$ and the blind individual were exposed to a series of 4 min light exposures at eight different wavelengths (420, 450, 480, 505, $530,555,585$, and $620 \mathrm{~nm}$ ). Participants received a fixed-irradiance light exposure of $13 \log$ photons $\mathrm{cm}^{-2} \mathrm{~s}^{-1}$ at each wavelength, with the order of presentation randomized. Participants E-H were exposed to each wavelength of light twice on different study days, and pupillary responses were averaged between trials. Participant D was exposed to the eight-wavelength series of light exposures only once. Percentage pupillary constriction was determined using median pupil diameter measured during the fourth minute of the light exposure. Spectral responses in the blind individual were fit with a fourparameter Gaussian equation as follows:

$$
y=y_{0}+a e^{\left[-0.5\left(\frac{x-x_{0}}{b}\right)^{2}\right]} .
$$

The best-fit parameter $x_{0}$ was used to estimate peak spectral sensitivity (SigmaPlot 11). Residuals were normally distributed ( $W=0.89 ; p=$ 0.24 ). In sighted participants, pupillary constriction responses at different wavelengths were compared by one-way repeated-measures ANOVA.

Experiment 3: fast kinetics of pupillary constriction. To examine the time course of pupillary constriction and dilation after light exposure onset and offset, respectively, we analyzed data collected in Experiment 1 from sighted participants $(n=3 ; \mathrm{A}, \mathrm{B}, \mathrm{D})$ and in Experiments 1 and 2 in the blind individual. We defined response latency as the duration of time that it took for pupil diameter to decrease by $20 \%$ after the onset of the light stimulus, measured relative to each person's maximum pupillary constriction response. For example, if a person's minimum pupil diameter $\left(d_{\text {min }}\right)$ was $2 \mathrm{~mm}$ during exposure to 2500 lux of bright light, and his dark-adapted pupil diameter $\left(d_{\max }\right)$ was $7 \mathrm{~mm}$, the $20 \%$ threshold for determining response latency after the onset of light exposure would be 6 $\mathrm{mm}: d_{\max }-\left[\left(d_{\max }-d_{\min }\right) \times 0.2\right]$. We chose a $20 \%$ threshold empirically based on the observation that random fluctuations in pupil size rarely exceed this level in darkness; hence a decrease in pupil size beyond this threshold can be attributed to the light stimulus rather than random physiologic noise. In normally sighted participants, data from 39 trials were analyzed in which pupillary light response magnitude exceeded the $20 \%$ threshold. In the blind participant, data from 13 trials met this criterion. After the light stimulus was extinguished, we measured the duration of time that it took for the pupil to dilate to $80 \%$ of the darkadapted size measured before the onset of the light stimulus. Pearson's correlation analysis was performed to examine the strength of the linear relationship between pupillary light reflex dynamics (i.e., response latency and time to redilate) versus median percentage pupillary constric- tion during the light exposure. The slopes of regression lines were compared by analysis of covariance.

Experiment 4: exposure to alternating light and darkness. Sighted participants $(n=4 ; \mathrm{E}-\mathrm{H})$ and the blind individual were exposed to continuous or intermittent light for $4 \mathrm{~min}$. Each intermittent light exposure session consisted of alternating $5 \mathrm{~s}$ episodes of fixed-irradiance $480 \mathrm{~nm}$ light ( $13 \log$ photons $\mathrm{cm}^{-2} \mathrm{~s}^{-1}$ ) and darkness for a total of 24 cycles of alternating exposure to light and darkness. In a different set of light exposures, participants were exposed to $5 \mathrm{~s}$ of the $480 \mathrm{~nm}$ light stimulus, followed by $15 \mathrm{~s}$ of darkness (i.e., individuals were exposed to 12 cycles of light and darkness during the 4 min intermittent light exposure session).

Experiment 5: long-duration exposure to continuous light. In pilot studies, we observed a gradual reduction in pupillary constriction, termed pupillary escape, in sighted individuals (I-K) exposed continuously to narrow-bandwidth light for 30-90 $\mathrm{min}$ (data not shown). Based on these results, we systematically compared PLR responses in sighted participants $(n=6 ; \mathrm{L}-\mathrm{Q})$ exposed to $90 \mathrm{~min}$ of 480 versus $555 \mathrm{~nm}$ light. Before each light exposure, participants were kept in darkness for $45 \mathrm{~min}$. Thereafter, participants were exposed to 480 or $555 \mathrm{~nm}$ light at three irradiances $\left(11.5,12.5\right.$, or $13.5 \log$ photons $\left.\mathrm{cm}^{-2} \mathrm{~s}^{-1}\right)$ with the order of exposure randomized. To reduce the size of the data set, median pupil diameter was determined every $30 \mathrm{~s}$. In 9 of 36 trials, pupil diameter could not be determined due to data loss. In the remaining 27 trials, median pupil diameter during exposure to 480 versus $555 \mathrm{~nm}$ light was compared at different irradiance levels by two-way ANOVA. The blind participant was exposed to $40 \mathrm{~min}$ of 480 versus $555 \mathrm{~nm}$ light, with light exposures matched by photon density (12.0 and $13.0 \mathrm{log}$ photons $\mathrm{cm}^{-2} \mathrm{~s}^{-1}$ ).

Experiment 6: long-duration exposure to intermittent light. In preliminary studies, we found that long-duration exposure to intermittent light ( $\geq 30 \mathrm{~min} ; 1 \mathrm{~Hz}$ ) could elicit sustained pupillary constriction in normally sighted individuals (R, S) (data not shown). We therefore systematically examined PLR responses in sighted participants $(n=6 ; \mathrm{E}, \mathrm{T}, \mathrm{U}, \mathrm{V}, \mathrm{W}, \mathrm{X})$ who were given a series of continuous or intermittent light exposures using an LCD monitor. Intermittent light exposures consisted of alternating episodes of green light $\left(12.0 \mathrm{log}\right.$ photons $\mathrm{cm}^{-2} \mathrm{~s}^{-1}, 0.36 \mu \mathrm{W}$ $\mathrm{cm}^{-2}$; peak spectral emission at $\left.543 \mathrm{~nm}\right)$ and a black LCD screen $(\sim 0.22$ $\mu \mathrm{W} \mathrm{cm}{ }^{-2}$ ), generated using E-prime software (Psychology Software Tools). In a within-subjects design, participants were exposed to $30 \mathrm{~min}$ of continuous green light or $30 \mathrm{~min}$ of intermittent green light at 0.1 , $0.25,0.5,1,2$, or $4 \mathrm{~Hz}$. Participants were exposed to each condition twice, with the order of light exposures chosen randomly. In each participant, median percentage pupillary constriction from each pair of trials was averaged, and within-subjects differences for pupillary constriction in response to different intermittent light stimuli were compared by oneway repeated-measures ANOVA.

\section{Results}

\section{Experiment 1: visual photoreceptors are required for driving the pupillary light reflex at low irradiances}

To examine the relative roles of melanopsin and rod-cone photoreceptors in mediating pupillary light responses, we constructed irradiance-response curves to $2 \mathrm{~min}$ of exposure to narrow-bandwidth $480 \mathrm{~nm}$ light in normally sighted individuals $(n=3)$ and in a blind individual without rod and cone function. Compared with sighted participants, the blind individual showed a marked reduction in PLR sensitivity at low irradiances (Fig. $1 A, B)$. As a result, the dynamic range of sensitivity was much smaller in the blind participant, spanning $<3$ log units. In contrast, pupil diameter in sighted participants changed dynamically over the entire range of irradiances tested (9-14 log photons $\left.\mathrm{cm}^{-2} \mathrm{~s}^{-1}\right)$. The $\mathrm{ED}_{50}$ of the dose-response curve was $0.82 \mathrm{log}$ units higher in the blind individual (Fig. $1 B$ ), indicating a strong reduction in PLR sensitivity in the absence of rod and cone function $\left(F_{(1,25)}=15.91 ; p<0.001\right)$. The slopes of the dose-response curves also differed significantly $\left(F_{(1,25)}=25.84 ; p<0.001\right)$; pupillary constriction responses were similar only at high irradi- 
A
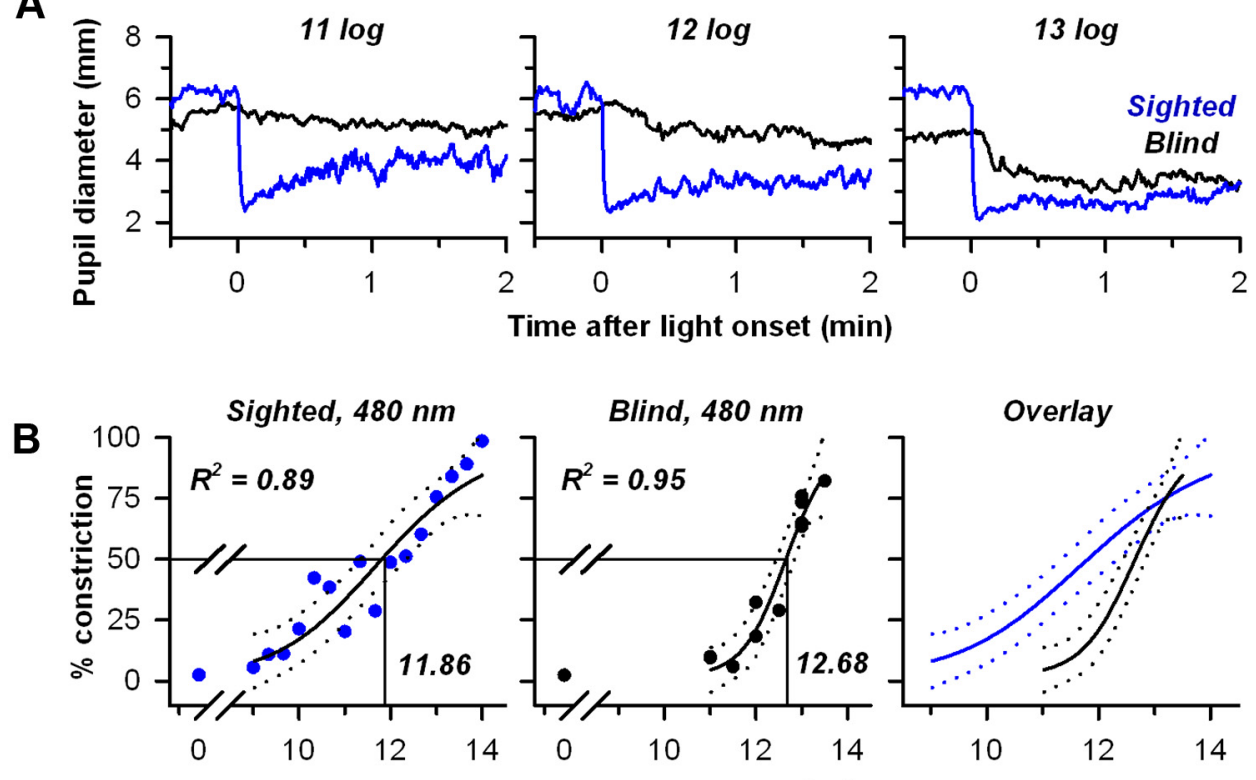

C

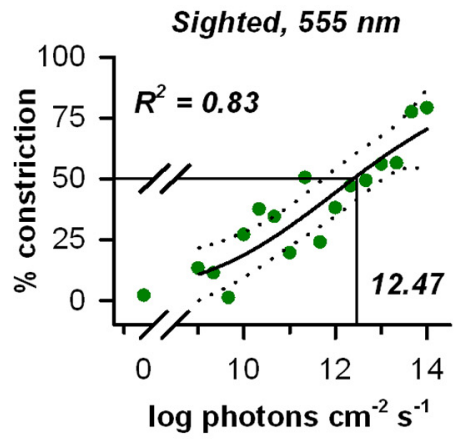

$\log$ photons $\mathrm{cm}^{-2} \mathrm{~s}^{-1}$

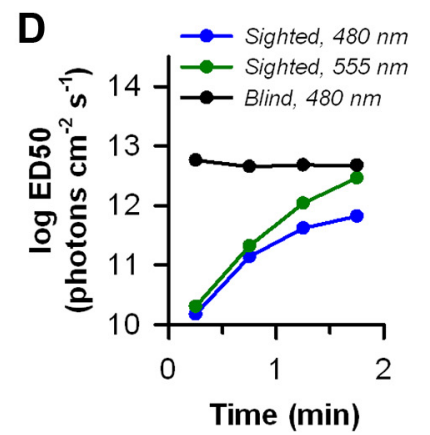

$\mathbf{F}$

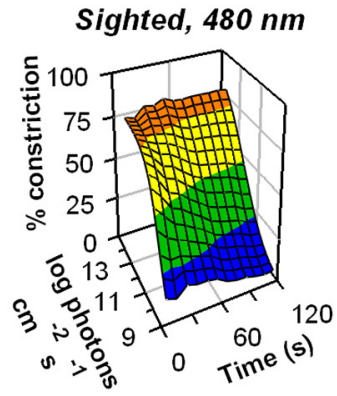

Sighted, $555 \mathrm{~nm}$

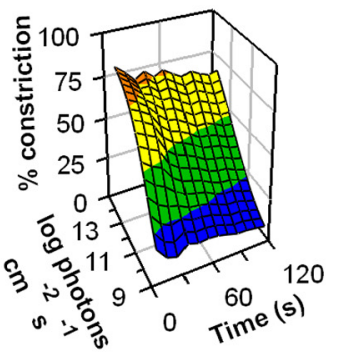

Blind, $480 \mathrm{~nm}$

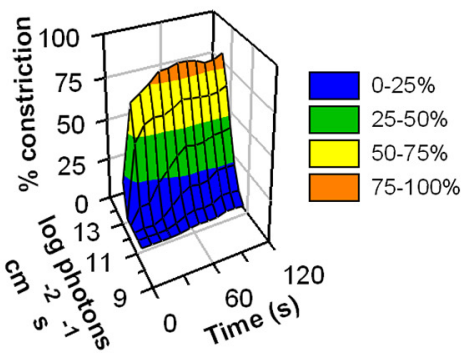

\section{G}

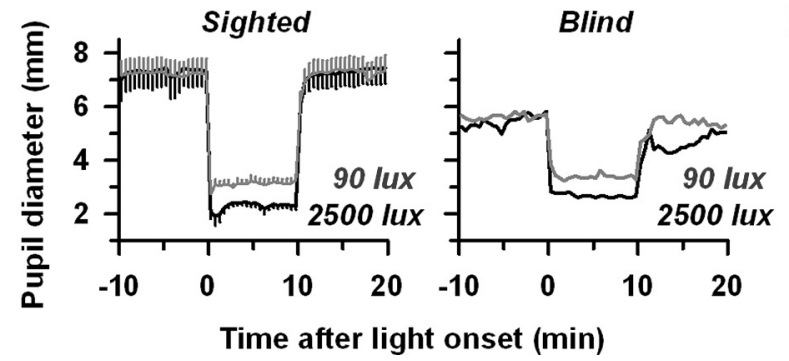

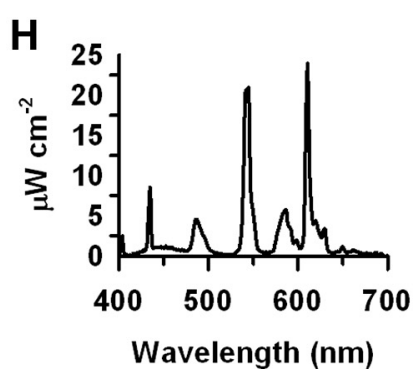

Figure 1. Visual photoreceptors mediate pupillary constriction at low irradiances. $\boldsymbol{A}$, Pupillary constriction responses are shown in a normally sighted participant (blue traces) and in a blind individual without rod and cone function (black traces) during exposure to 2 min of narrow-bandwidth $480 \mathrm{~nm}$ light. Irradiance levels are indicated at the top of each plot (in photons centimeter ${ }^{-2}$ second $^{-1}$ ). $\boldsymbol{B}$, Dose-response curves for pupillary constriction to $480 \mathrm{~nm}$ light are shown for normally sighted participants ( $n=3$; blue circles, left panel) and in the blind individual (black circles, center panel), assessed 90-120 s after the onset of light exposure. Best-fit dose-response functions are shown with confidence intervals indicated by the dotted lines. The drop lines show the log $\mathrm{ED}_{50}$ of each dose-response function. Dose-response curves are overlaid in the far right panel, demonstrating reduced sensitivity to $480 \mathrm{~nm}$ light at low irradiances in the (Figure legend continues.) 
ances ( $\geq 13 \log$ photons $\left.\mathrm{cm}^{-2} \mathrm{~s}^{-1}\right)$ and diverged as irradiance was decreased. To examine further the role of photopic vision $\left(\lambda_{\max }=555 \mathrm{~nm}\right)$ and melanopsin-based photoreception in mediating pupillary light responses, we compared dose-response curves to 555 versus $480 \mathrm{~nm}$ light in normally sighted individuals (Fig. $1 C-E$ ). During the first $90 \mathrm{~s}$ of exposure to light, the $\mathrm{ED}_{50}$ and slope of dose-response curves were similar $\left(F_{(1,28)}\right.$ $\left.<2.30, p>0.14 ; F_{(1,28)}<1.52, p>0.22\right)$. During the next $30 \mathrm{~s}$ (i.e., 90-120 s after light onset), however, the $\mathrm{ED}_{50}$ of the dose-response to $555 \mathrm{~nm}$ light was significantly greater $\left(F_{(1,28)}=4.61 ; p=0.04\right)$, indicating that pupillary constriction was short-wavelength (blue)-shifted by the end of the second minute of exposure to continuous light (Fig. 1D). The difference in log relative sensitivity ( $-0.61 \log$ units) was still less than the predicted difference at these wavelengths for a vitamin A1-based photopigment with peak sensitivity to 480 nm light ( $-0.95 \log$ units), however, suggesting that melanopsin is not the only photopigment driving the pupillary light response (Fig. $1 E$ ).

To examine the time course of pupillary constriction in greater detail, we constructed dose-response curves for exposure to 480 and $555 \mathrm{~nm}$ light in $10 \mathrm{~s}$ bins (Fig. $1 F$ ). In sighted participants, only high-irradiance $480 \mathrm{~nm}$ light $\left(>13 \log\right.$ photons $\mathrm{cm}^{-2}$ $\mathrm{s}^{-1}$ ) elicited a steady pupillary constriction response during exposure to 2 min of continuous light. At lower irradiances, and for all exposures to $555 \mathrm{~nm}$ light, pupillary constriction decreased over time. In contrast, pupillary constriction in the blind individual increased across the first minute of exposure to $480 \mathrm{~nm}$ light until reaching a steady response (Fig. $1 F$ ). Together, these results suggest that rod-cone photoreceptors are required from normal pupillary responses to short-wavelength blue light early in the light exposure.

Next, we examined the contribution of visual photoreceptors versus melanopsin to the PLR in room light (Fig. 1G,H). During exposure to 90 lux of polychromatic (4100K) white light for 10 min, median percentage pupillary constriction in the blind individual $(80.0 \%)$ was similar to that observed in sighted participants $(83.8 \pm 2.7 \%)$, suggesting that, in the absence of rod and cone function, melanopsin-mediated PLR responses are driven strongly by ordinary room light.

\section{Experiment 2: short-wavelength sensitivity of pupillary constriction in a blind individual}

Next, we compared spectral responses of the PLR in participants with normal vision $(n=5)$ versus the blind individual (Fig. $2 A$ ). Participants were exposed to $4 \mathrm{~min}$ of light at eight different

\section{$\leftarrow$}

(Figure legend continued.) blind participant. C, The dose-response curve for pupillary constriction is shown in normally sighted participants exposed to $555 \mathrm{~nm}$ light. $\boldsymbol{D}$, The $\log \mathrm{ED}_{50}$ value is shown for dose-response curves to 480 versus $555 \mathrm{~nm}$ light in 30 s bins during exposure to $2 \mathrm{~min}$ of continuous light (left panel). Over time, there was a progressive decrease in sensitivity in sighted participants, with a greater reduction in sensitivity to $555 \mathrm{~nm}$ light. By comparison, in the blind individual the $\log \mathrm{ED}_{50}$ value for pupillary constriction in response to $480 \mathrm{~nm}$ (black circles) was stable over time. $E$, In sighted individuals, the difference in $\log \mathrm{ED}_{50}$ values ( $480 \mathrm{vs} 555 \mathrm{~nm}$ light) is shown during exposure to 2 min of continuous light. The dotted line shows the predicted difference in log relative sensitivity at these wavelengths for a vitamin A1-based photopigment with peak sensitivity to $480 \mathrm{~nm}$ light. $\boldsymbol{F}$, Dose-response curves are shown in $10 \mathrm{~s}$ bins for sighted individuals exposed to 480 versus $555 \mathrm{~nm}$ light, and in the blind patient exposed to $480 \mathrm{~nm}$ light. G, Pupillary constriction is shown in normally sighted participants $(n=4)$ and in a blind individual exposed to 10 min of polychromatic white light (4100K). The black and gray traces show responses to 2500 and 90 lux of light, respectively. Error bars indicate SEM. $\boldsymbol{H}$, The spectral composition of the fluorescent white light source is shown.
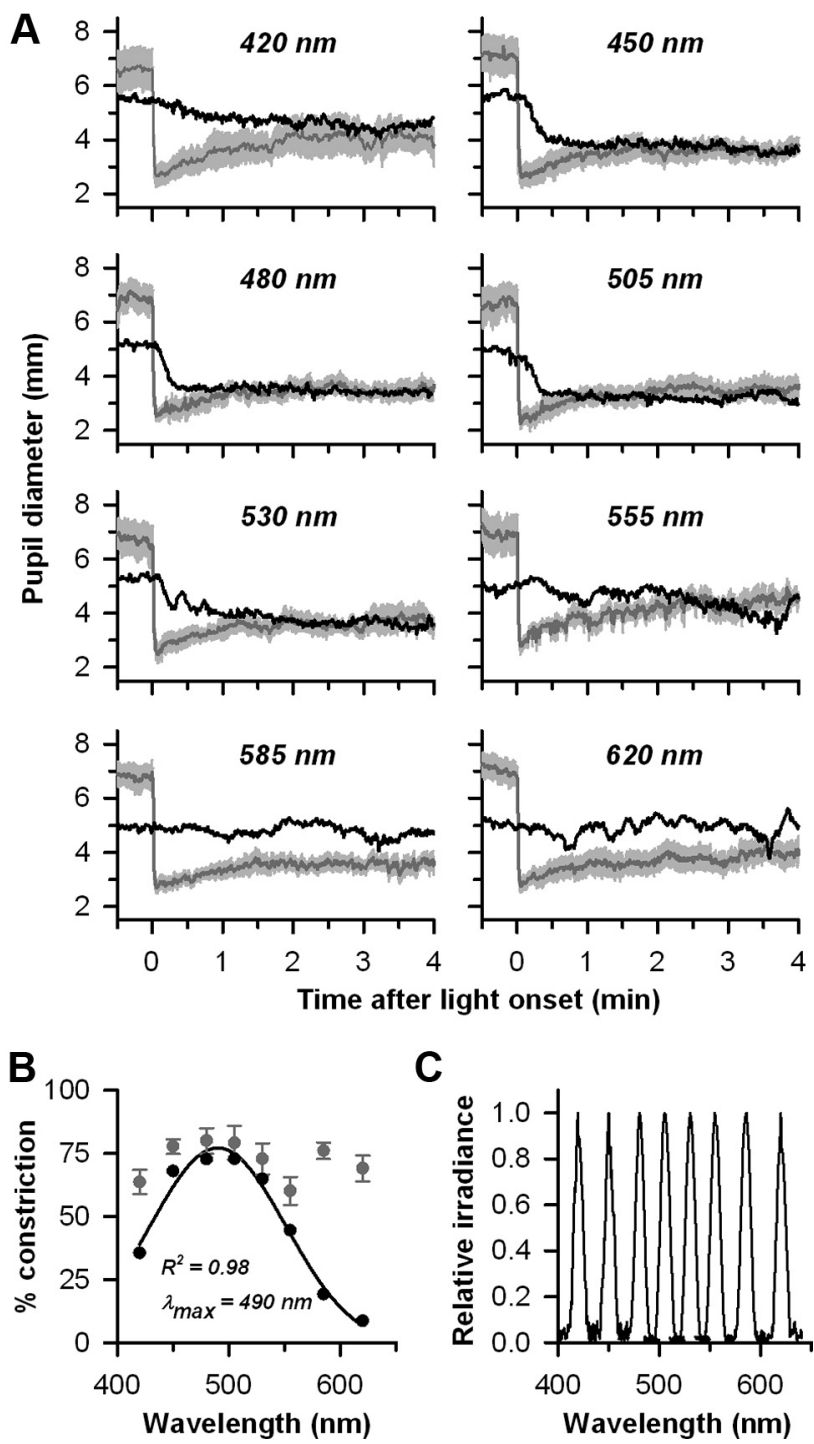

C

Figure 2. Spectral responses of pupillary constriction during exposure to continuous light. $\boldsymbol{A}$, Pupillary light responses are shown in normally sighted individuals ( $n=5$; gray traces) and in a blind participant without rod and cone function (black traces). Participants were exposed to 4 min of fixed-irradiance ( $13 \mathrm{log}$ photons $\mathrm{cm}^{-2} \mathrm{~s}^{-1}$ ) narrow-bandwidth light at eight different wavelengths. Error bars shown in light gray indicate SEM. $\boldsymbol{B}$, Spectral responses in sighted individuals and the blind individual are shown by gray and black circles, respectively. Percentage constriction was measured during the fourth minute of light exposure and plotted by corneal irradiance. The black trace shows the best-fit Gaussian function for spectral responses in the blind individual; peak spectral sensitivity is observed in the short-wavelength portion of the visual spectrum. C, For each of the light exposures given, relative irradiance levels and spectral composition are shown.

wavelengths matched for photon density $\left(13 \log\right.$ photons $\mathrm{cm}^{-2}$ $\mathrm{s}^{-1}$ ). In sighted individuals, response magnitude of the PLR was similar across different wavelengths (ANOVA, repeated measures; $F_{(4,7)}=2.36, p=0.05$, but with no significant differences following multiple-comparison tests). In all five participants, however, average pupillary constriction was greater in response to 480 versus $555 \mathrm{~nm}$ light. In the blind participant, pupillary constriction was short-wavelength sensitive with a fitted peak sensitivity to $490 \mathrm{~nm}$ light $\left(R^{2}=0.98 ;\right.$ Fig. $\left.2 B\right)$. At all wavelengths of light that were examined (Fig. 2C), sighted participants showed stronger pupillary constriction than the blind individual, and the difference in response magnitude was greatest for longwavelength light in the red portion of the visual spectrum. 
A

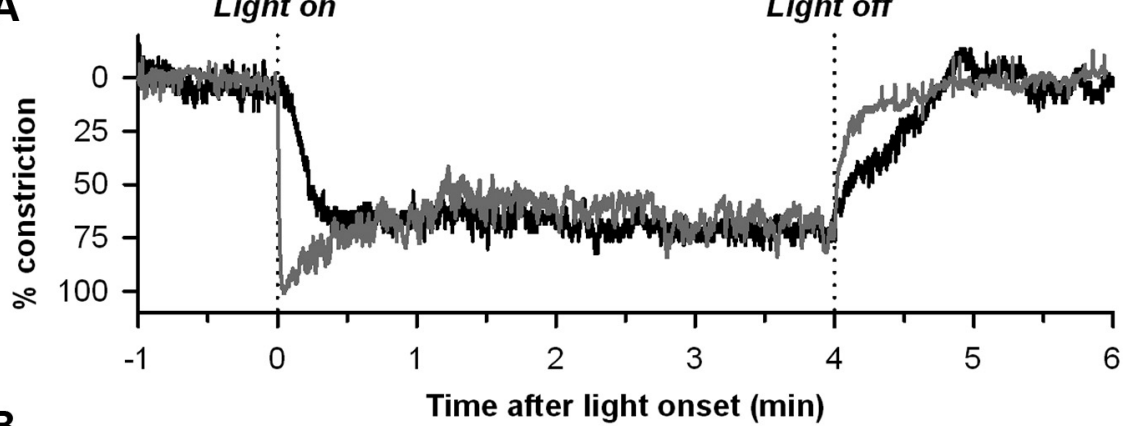

B

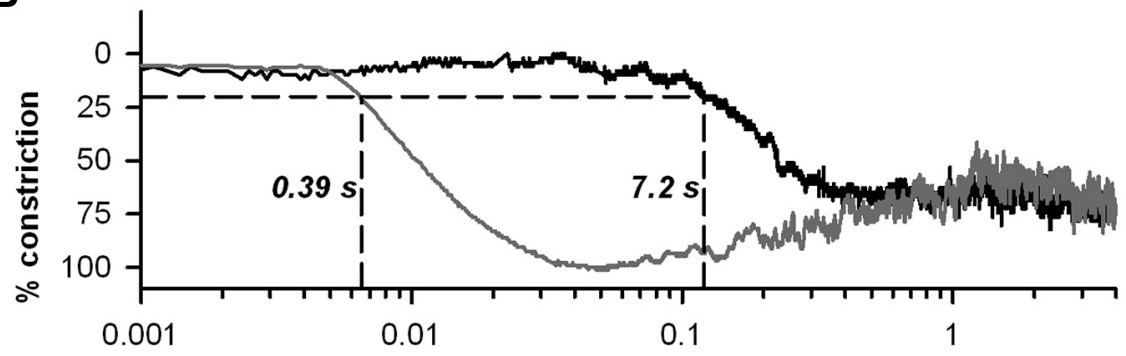

C

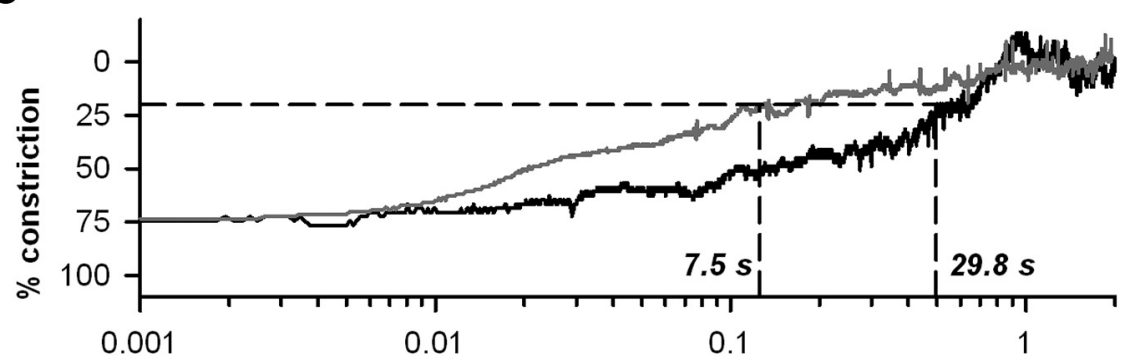

Time after light offset (min)
D

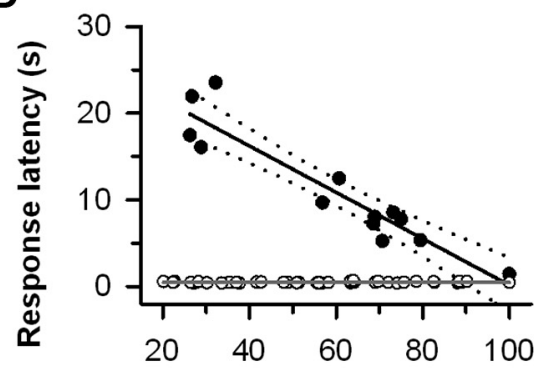

Sustained constriction (\%)

$\mathbf{F}$

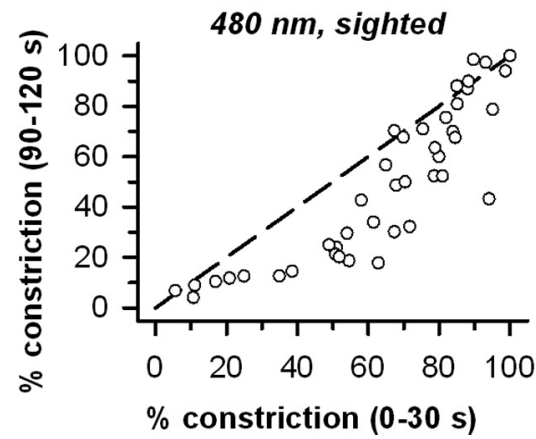

$E$

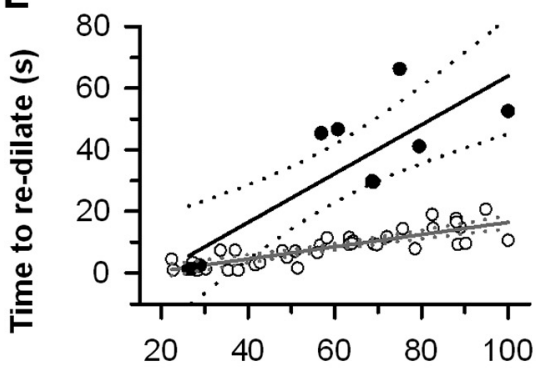

Sustained constriction $(\%)$

$\mathbf{G}$

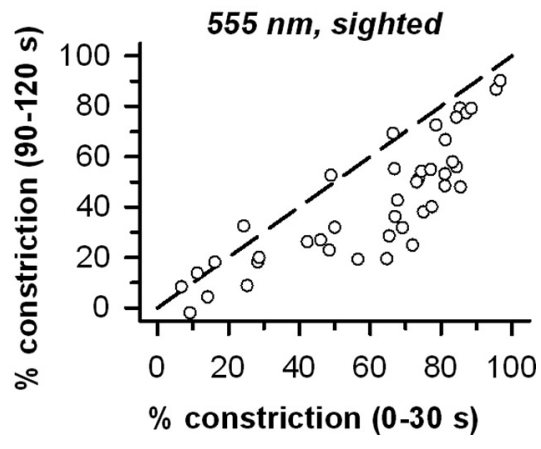

Figure 3. Kinetics of pupillary constriction following light exposure onset and offset. $\boldsymbol{A}$, Representative traces are shown for pupillary constriction in a sighted participant (gray) and in a blind individual without rod and cone function (black), matched for
Experiment 3: visual photoreceptors mediate fast kinetics of the pupillary light reflex

Next, we examined the time course of pupillary constriction in relation to light stimulus onset and offset. Compared with sighted participants exposed to $480 \mathrm{~nm}$ light, the pupil responded sluggishly in the blind individual after the onset of the light stimulus (Fig. $3 A, B$ ), taking at least several seconds to show a detectable response for most exposures. Similarly, after the light was extinguished, the blind individual's pupil dilated very slowly toward the dark-adapted pupil size (Fig. $3 A, C)$. We hypothesized that rapid versus sustained PLR responses in sighted participants were driven by different photoreceptor mechanisms. To address this possibility, we examined the relationship between PLR onset latency and the magnitude of pupillary constriction during continuous exposure to light. We defined pupillary constriction response latency as the duration of time from light onset until the pupil constricted by $20 \%$ (Fig. $3 D)$. In sighted participants $(n=3)$, response latency $(478 \pm 11.5 \mathrm{~ms})$ did not correlate with the magnitude of sustained pupillary constriction $(r=0.15 ; p=0.38)$ (i.e., there was no relationship between the initial rapid PLR response and the magnitude of pupillary constriction during exposure to continuous light). In contrast, response latency in the blind participant decreased linearly with increasing magnitude of sustained pupillary constriction (Pearson's correlation coeffi-

$\leftarrow$

median response magnitude. Pupillary constriction was sluggish in the blind individual after light onset, and slow to redilate back to baseline after the offset of the light stimulus. $\boldsymbol{B}$, Pupillary constriction during the light stimulus is replotted from $A$ on a logarithmic scale to demonstrate the difference in response latency with and without visual photoreceptors (gray and black traces, respectively). C, Similarly, pupillary constriction after the offset of the light stimulus is shown to illustrate the relatively sluggish dilation of the blind participant's pupil toward the dark-adapted state. $\boldsymbol{D}$, Response latency in the blind individual (black trace) was negatively correlated with the magnitude of sustained pupillary constriction, whereas response latency did not correlate with strength of pupillary constriction during exposure to continuous light in normally sighted individuals (open circles). $\boldsymbol{E}$, The rate at which the pupils redilated after light exposure offset was approximately five times slower in the blind individual relative to responses measured in normally sighted participants. $\boldsymbol{F}$, In sighted participants, the relationship was nonlinear between pupillary constriction near the beginning ( $0-30 \mathrm{~s}$ ) and end ( $90-120 \mathrm{~s})$ of exposure to $2 \mathrm{~min}$ of continuous $480 \mathrm{~nm}$ light. $G$, Similarly, the decrease in strength of pupillary light responses was nonlinear during continuous exposure to $555 \mathrm{~nm}$ light. The dashed line shows the line of unity. 
cient; $r=-0.94, p<0.001)$. These data suggest that, in normally sighted individuals, the rapid rod-cone response masks the slower contribution of melanopsin to pupillary constriction near the beginning of light exposure. For relatively weak, sustained pupillary constriction responses (range, 26-33\%), response latency was $\sim 40$ times slower in the blind participant compared with sighted participants.

Next, we examined the amount of time it took for the pupils to dilate back to $80 \%$ of the dark-adapted size after the offset of the light stimulus (Fig. $3 E$ ). In sighted participants, the time required for the pupils to dilate increased linearly with the strength of pupillary constriction during the preceding light exposure $(r=0.84 ; p<0.001)$, with maximum dilation time of $\sim 15 \mathrm{~s}$ for the brightest light stimuli tested. In the blind individual, the time it took for the pupils to redilate also increased linearly with increasing magnitude of pupillary constriction (Pearson's correlation; $r=0.85, p=$ 0.002 ), but the rate of recovery was much slower than in sighted participants, as demonstrated by the difference in slopes $\left(F_{(1,43)}\right.$ $=39.59 ; p<0.001$ ).

During exposure to continuous light, the relative decrease in pupillary constriction over time in sighted individuals was related to the strength of pupillary constriction early in the light exposure (Fig. $3 F, G)$. We assessed this by comparing percentage pupillary constriction during the first $30 \mathrm{~s}$ of light exposure with pupillary constriction 90-120 s after light onset. The relationship was nonlinear, such that the decrease in pupillary constriction over time was greatest for responses that were in the $\sim 40-80 \%$ range near the beginning of light exposure. For trials in which median pupillary constriction exceeded $\sim 80 \%$ during the first 30 s, pupillary light responses to $480 \mathrm{~nm}$ light were relatively stable over time and approached the line of unity (Fig. $3 F$ ), whereas a small reduction in pupillary constriction was observed over time even for the strongest responses to $555 \mathrm{~nm}$ light (Fig. 3G).

Experiment 4: visual photoreceptors are required for pupillary responses to track intermittent light stimuli Next, we assessed pupillary responses to shorter-duration and intermittent light stimuli $\left(480 \mathrm{~nm} ; 13 \log\right.$ photons $\left.\mathrm{cm}^{-2} \mathrm{~s}^{-1}\right)$. In contrast to sighted participants $(n=4)$, exposure to a single $6 \mathrm{~s}$ pulse of light elicited a weak transient PLR response in the blind individual that was much smaller than the response to continuous light (Fig. 4A). Based on the slow kinetics of pupillary constriction and dilation in the blind individual, we hypothesized that his PLR response would sum over short episodes of darkness, due to sustained activation of melanopsin cells after light expoleft panels indicate SEM.
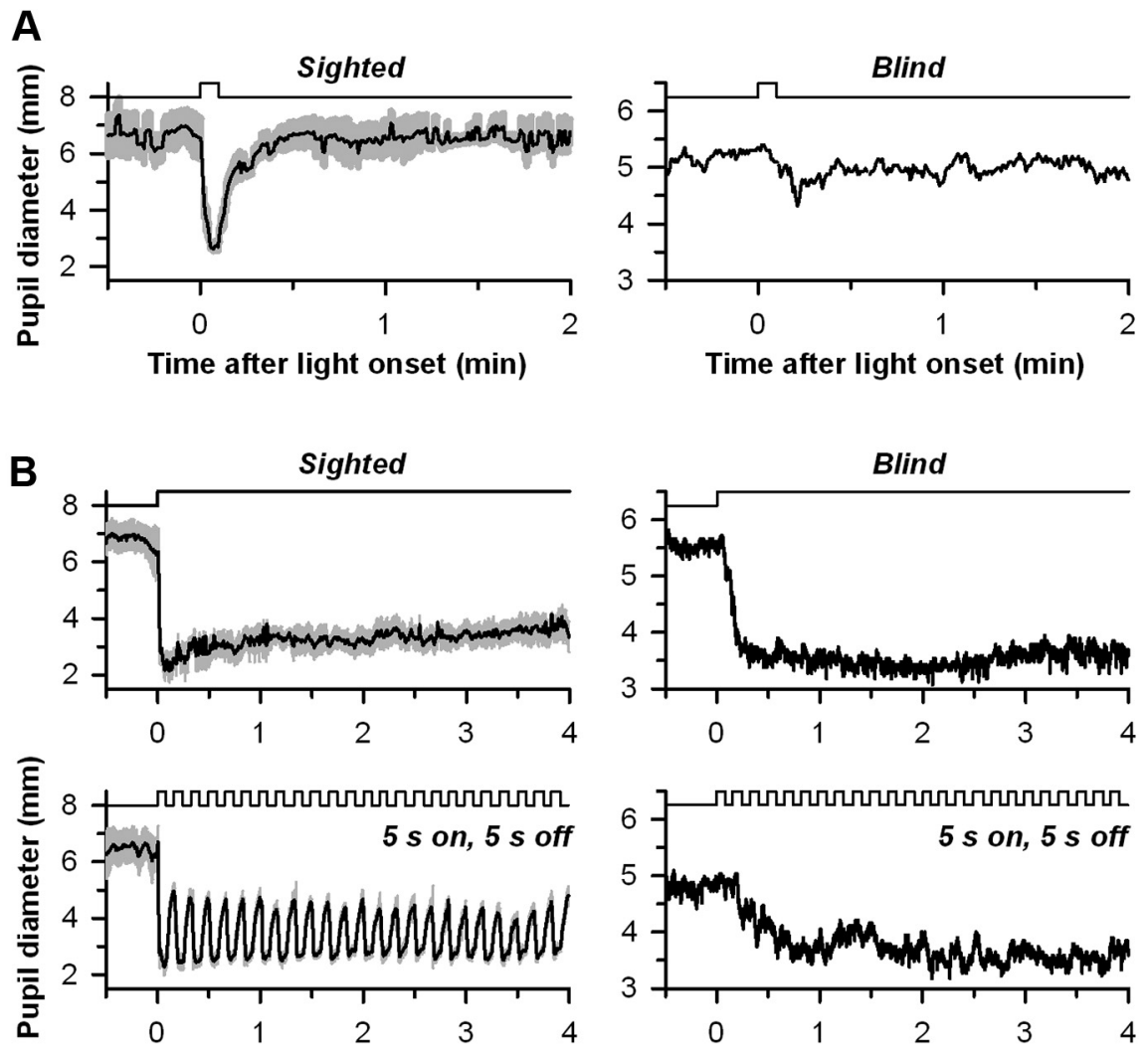

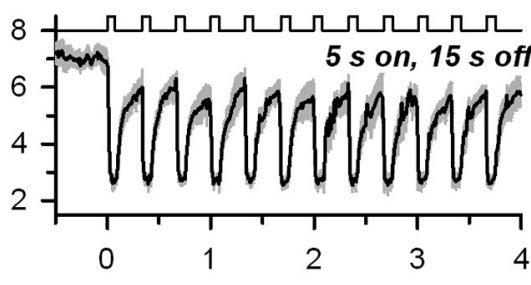

Time after light onset (min)

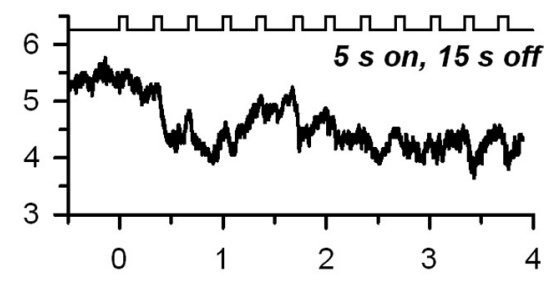

Time after light onset (min)
Figure 4. Visual photoreceptors are required for pupillary responses to track intermittent light stimuli. A, Pupillary constriction is shown in normally sighted individuals $(n=4)$ and in a blind patient without rod and cone function in response to a single $6 \mathrm{~s}$ pulse of $480 \mathrm{~nm}$ light ( $13 \mathrm{log}$ photons $\mathrm{cm}^{-2} \mathrm{~s}^{-1}$ ). B, Participants were exposed to 4 min of continuous or intermittent $480 \mathrm{~nm}$ light pupillary constriction (top row). During an intermittent light stimulus with alternating periods of $5 \mathrm{~s}$ of light and $5 \mathrm{~s}$ of darkness, ly sighted participants' pupils were able to track each successive light pulse, whereas in the blind individual, responses were 列 $5 \mathrm{~s}$ of light and $15 \mathrm{~s}$ of darkness, the blind individual's pupil was still able to integrate light information across longer of darkness (bottom row). The pattern of light exposure is shown at the top of each plot, with upward deflection indicating times when participants were exposed to light. To highlight differences in pupillary constriction responses to intermit-

sure offset (Gamlin et al., 2007). To examine this, we exposed sighted participants $(n=4)$ and the blind individual to an intermittent light stimulus consisting of $5 \mathrm{~s}$ of $480 \mathrm{~nm}$ light (13 log photons $\mathrm{cm}^{-2} \mathrm{~s}^{-1}$ ), followed by $5 \mathrm{~s}$ of darkness (Fig. $4 B$, middle panel) for $4 \mathrm{~min}$. In the blind individual, the pupil constricted slowly over several pulses of light until reaching a stable response that was essentially identical with pupil diameter measured in response to $4 \mathrm{~min}$ of continuous light. The PLR in the blind participant was also able to integrate light information when $5 \mathrm{~s}$ pulses of intermittent light were followed by $15 \mathrm{~s}$ of darkness (Fig. $4 B$, bottom panel), with strong pupillary constriction following the second light pulse. By comparison, pupil diameter in sighted participants $(n=4)$ tracked the intermittent light 
A
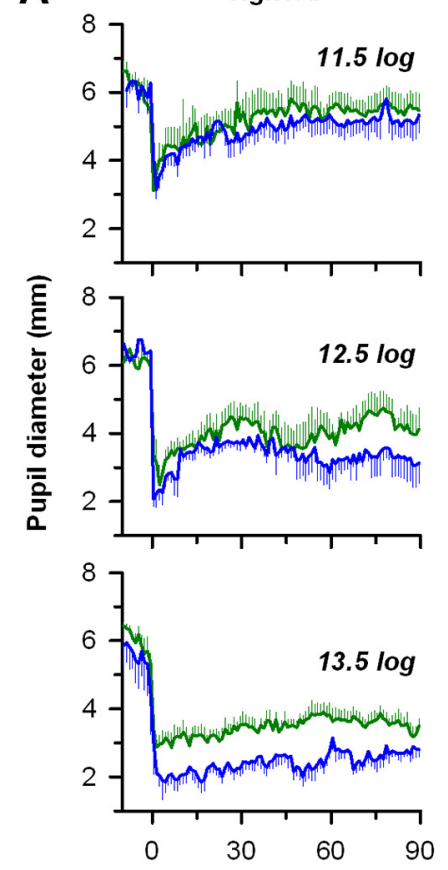

Time after light onset (min)

Figure 5. Pupillary escape occurs gradually in the presence of continuous low irradiance light. $A$, Pupillary constriction is shown in normally sighted individuals $(n=6)$ during exposure to $90 \mathrm{~min}$ of $480 \mathrm{~nm}$ light (blue traces) versus $555 \mathrm{~nm}$ light (green traces). Irradiance levels are indicated at the top of each plot (in photons centimeter ${ }^{-2}$ second ${ }^{-1}$ ). Error bars indicate SEM. $B$, In a blind individual without rod and cone function, pupillary constriction remained relatively stable during $40 \mathrm{~min}$ of exposure to 480 or $555 \mathrm{~nm}$ light.

stimulus precisely over time, with each successive light pulse eliciting a response similar to the one preceding it.

\section{Experiment 5: pupillary constriction decreases gradually in continuous light at low irradiance levels}

In previous studies, it was reported that the PLR reaches a steadystate response after just a few minutes of exposure to a fixedirradiance light stimulus (Mure et al., 2009). For light exposure irradiances $<13 \log$ photons $\mathrm{cm}^{-2} \mathrm{~s}^{-1}$, however, we found that pupil size in sighted participants often increased gradually during short-duration light stimuli (Figs. $1 A, 2 A$ ), suggesting that pupil diameter had not yet reached a steady-state size. Moreover, in pilot studies, we found that pupil size continued to dilate slowly during exposure to 30-60 min of continuous light (data not shown). We therefore compared the pupillary light reflex in normally sighted participants $(n=6)$ in response to long-duration (90 min) 480 versus $555 \mathrm{~nm}$ light at three different irradiance levels $\left(11.5,12.5\right.$, and $13.5 \log$ photons $\left.\mathrm{cm}^{-2} \mathrm{~s}^{-1}\right)$. Although there was no interaction between irradiance and wavelength on median pupillary constriction $\left(F_{(1,21)}=0.69 ; p=0.512\right)$, there was a main effect of wavelength on pupillary constriction $\left(F_{(1,21)}=6.06 ; p=0.023\right)$, such that PLR responses were greater in response to $480 \mathrm{~nm}$ light versus $555 \mathrm{~nm}$ light. At the two lower irradiances tested, the pupils redilated gradually in continuous light, termed "pupillary escape," for at least $30 \mathrm{~min}$ after the onset of the light stimulus (Fig. 5A). By comparison, during exposure to higher-irradiance light $\left(13.5 \log\right.$ photons $\left.\mathrm{cm}^{-2} \mathrm{~s}^{-1}\right)$, there was very little change in pupil diameter over time. In contrast to sighted participants, we did not observe pupillary escape in the blind individual (Fig. 5B). Rather, pupil diameter in the blind individual remained stable for as long as the fixed-irradiance stimulus was presented $\left(13 \log\right.$ photons $\left.\mathrm{cm}^{-2} \mathrm{~s}^{-1}\right)$, and $480 \mathrm{~nm}$ light was more effective than $555 \mathrm{~nm}$ light at driving pupillary constriction.

\section{Experiment 6: intermittent light can be used to enhance pupillary constriction responses}

Given that pupillary escape in continuous light was observed only in sighted participants, and at relatively low irradiances, we hypothesized that the gradual reduction in PLR sensitivity over time was due to reduced drive from cone photoreceptors. If so, inserting short pulses of darkness during long-duration light stimuli would be expected to enhance pupillary constriction by giving cone photoreceptors the opportunity to dark adapt between light pulses. To test this possibility, sighted participants $(n=6)$ were exposed to $30 \mathrm{~min}$ of continuous green light $(543 \mathrm{~nm} ; 12 \mathrm{log}$ photons $\mathrm{cm}^{-2} \mathrm{~s}^{-1}$ ) or intermittent green light over a range of frequencies $(0.1-4 \mathrm{~Hz})$, administered using an LCD monitor (Fig. 6A). In continuous light, pupil diameter increased gradually during the $30 \mathrm{~min}$ exposure (Figs. $6 B, 7 A$ ), with a log-linear profile of pupillary escape (Fig. $7 B$ ), indicating that the rate of redilation of the pupils was greatest near the beginning of the light exposure, and decreased with increasing duration of exposure to light. By comparison, exposure to intermittent light elicited PLR responses that were more than twice as great, with very little recovery from pupillary constriction over time (Fig. $7 C$ ). At all frequencies tested, intermittent light elicited stronger and more sustained pupillary constriction responses relative to continuous light $\left(F_{(5,30)}=17.57 ; p<0.001\right.$; Figs. 6, 7).

\section{Discussion}

Our results show that rod-cone photoreceptors play an important role in driving pupillary constriction during exposure to continuous low-irradiance light, whereas melanopsin is the primary photopigment that drives sustained pupillary constriction in response to high-irradiance light. Rod-cone photoreceptors mediate rapid constriction of the pupils following light stimulus onset and allow the pupils to track high-frequency intermittent light stimuli. During exposure to continuous light, the relative contribution of cone photoreceptors to pupillary constriction decreases over time. By applying short-duration intermittent dark pulses, however, pupillary responses can be sustained and even enhanced, presumably by allowing cone photoreceptors time to dark adapt between light pulses.

In a blind individual without rod-cone function, pupillary constriction was preserved during exposure to high-irradiance $480 \mathrm{~nm}$ light, but weak or absent at lower irradiance levels. Similar results have been reported in rodless/coneless mice (Lucas et al., 2001) and dogs with sudden acquired retinal degeneration syndrome (Grozdanic et al., 2007). Our findings confirm in humans that melanopsin dominates the PLR at high irradiances (Lucas et al., 2003), whereas visual photoreceptors mediate pupillary constriction during exposure to continuous lowirradiance light. The threshold for pupillary constriction in the blind individual was close to $11 \log$ photons $\mathrm{cm}^{-2} \mathrm{~s}^{-1}$, which is consistent with results in $r d / r d c l$ mice and gnat $1^{-1-} \mathrm{cl}$ mice that lack rod-cone function (Lucas et al., 2003; Do et al., 2009), and monkeys with pharmacologic blockade of rod-cone signaling (Gamlin et al., 2007). These findings suggest that we were able to isolate melanopsin-driven pupillary responses in the blind patient, and that intrinsically photosensitive retinal ganglion cell (ipRGC) function and sensitivity might be conserved across different mammalian species. 
A
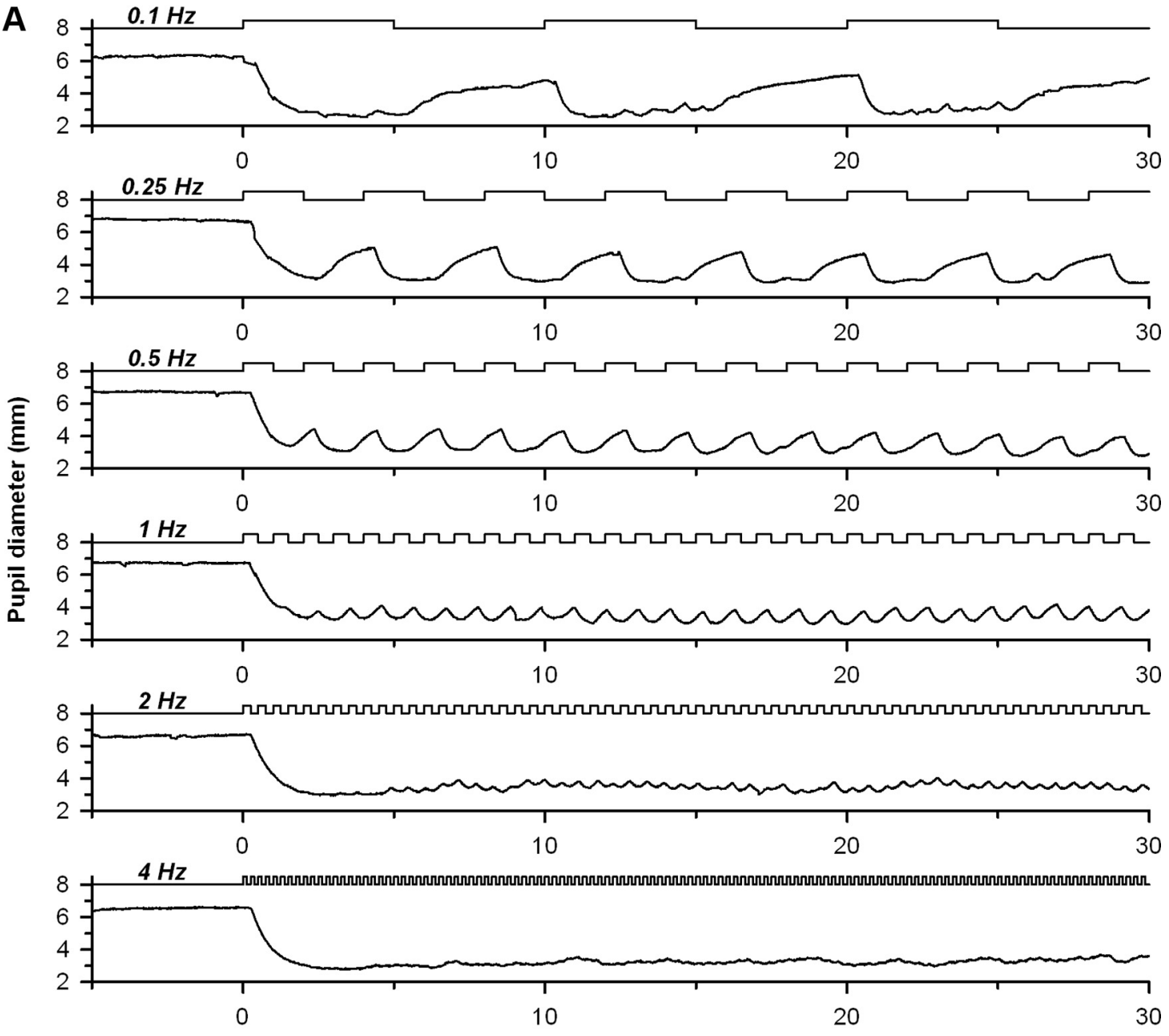

Time after light onset (s)
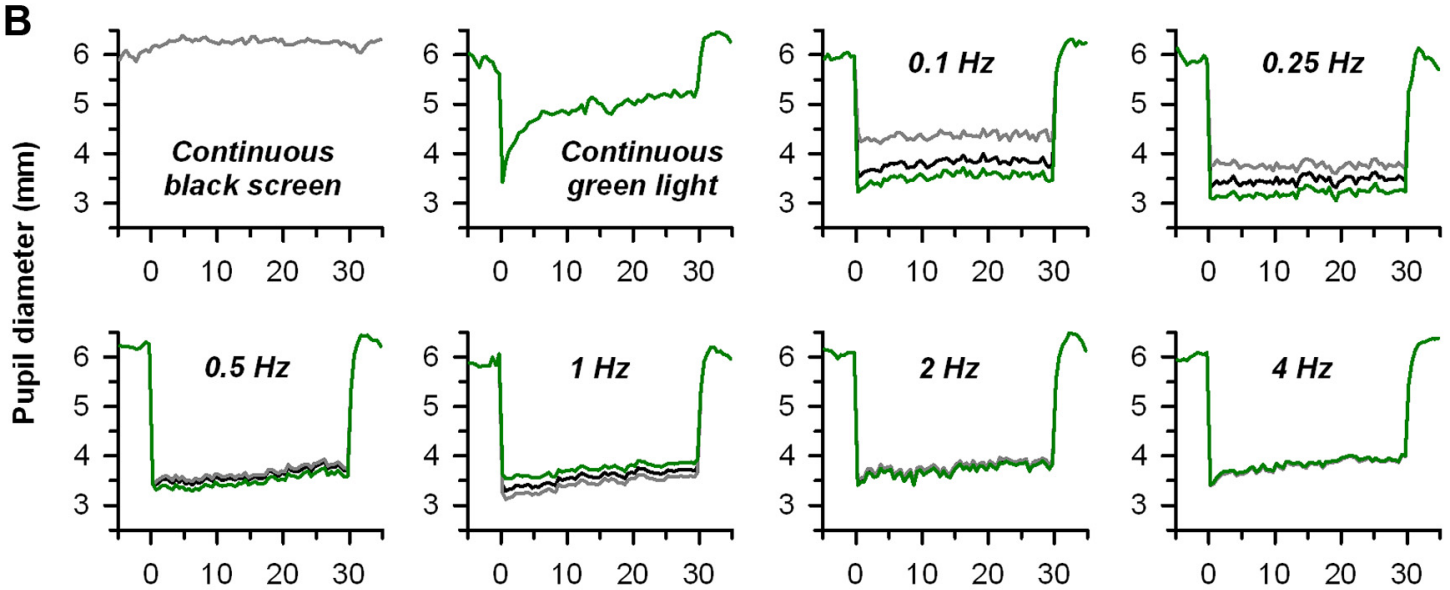

Time after light onset (min)

Figure 6. Pupillary responses to high-frequency intermittent light. $A$, Pupillary constriction responses are shown in a representative participant during the first $30 \mathrm{~s}$ of exposure to intermittent light. Intermittent green light $(0.1-4 \mathrm{~Hz})$ was given using an LCD screen $\left(543 \mathrm{~nm} ; 12 \log\right.$ photons $\left.\mathrm{cm}^{-2} \mathrm{~s}^{-1}\right)$. The frequency and pattern of light exposure are shown at the top of each trace. $\boldsymbol{B}$, Average pupillary constriction responses are shown in normally sighted individuals $(n=6)$ during exposure to $30 \mathrm{~min}$ of intermittent light at different frequencies. Pupil diameter during $0 \mathrm{~N}$ and $0 \mathrm{FF}$ pulses are shown by green and gray traces, respectively. The black traces show average pupil diameter in $30 \mathrm{~s}$ bins for both $0 \mathrm{~N}$ and $0 \mathrm{FF}$ pulses.

In sighted participants, we observed a short-wavelength shift in sensitivity during exposure to 2 min of light, suggesting a contribution from middle- and/or long-wavelength-sensitive cones early in the exposure (Mure et al., 2009). Consistent with this interpretation, the pupils showed sustained constriction during exposure to $4 \mathrm{~min}$ of $620 \mathrm{~nm}$ red light ( $13 \log$ photons $\mathrm{cm}^{-2} \mathrm{~s}^{-1}$; Fig. 2), but we cannot exclude a contribution from rod photoreceptors. By comparison, there was little or no response to long- 

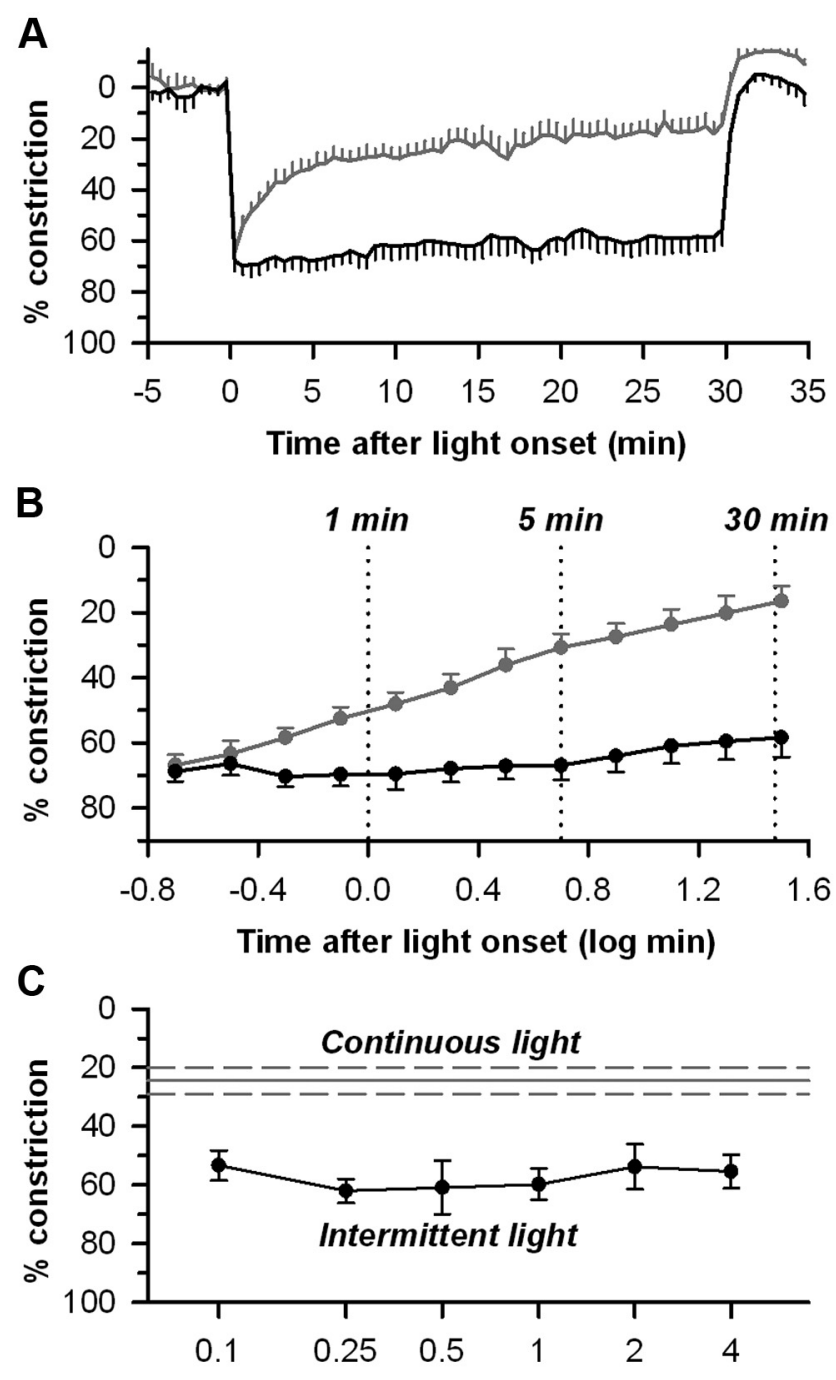

Frequency of intermittent light $(\mathrm{Hz})$

D

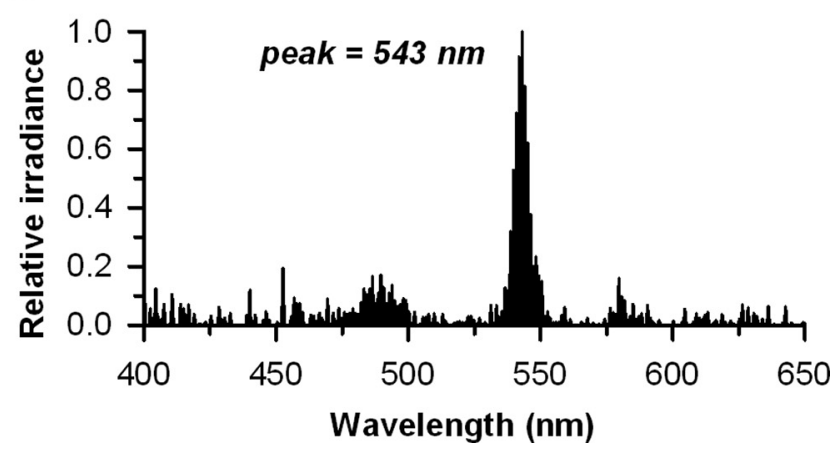

Figure 7. Exposure to intermittent light enhances pupillary constriction responses. $\boldsymbol{A}$, The pupillary light reflex is shown in sighted participants $(n=6)$ during exposure to 30 min of continuous green light (gray trace) versus intermittent green light at $1 \mathrm{~Hz}$ (black trace) using an LCD monitor. Intermittent light $\left(12 \log\right.$ photons $\left.\mathrm{cm}^{-2} \mathrm{~s}^{-1}\right)$ elicited pupillary constriction responses that were sustained and twice as great relative to exposure to continuous light at the same irradiance level. Error bars indicate SEM. $\boldsymbol{B}$, Data from $\boldsymbol{A}$ are rebinned and plotted on a logarithmic scale. Pupil diameter increased monotonically during exposure to $30 \mathrm{~min}$ of continuous green light (gray circles), whereas intermittent green light prevented pupillary escape (black circles). C, Median pupillary constriction was $\sim 25 \%$ during exposure to $30 \mathrm{~min}$ of continuous light, whereas intermittent light elicited pupillary constriction responses $>50 \%$ in the frequency range from 0.1 to $4 \mathrm{~Hz}$. D, Spectral characteristics are shown for the LCD green light stimulus. wavelength red light in the blind participant. Rather, the PLR was most sensitive to blue light, even though less short-wavelength light is transmitted to the retina as the lens ages (Brainard et al., 1997; Kessel et al., 2010) and pupillary responses were not corrected for preretinal lens absorption. Our findings in the blind patient are consistent with the spectral sensitivity of pupillary responses in an older blind individual (Zaidi et al., 2007) (87year-old participant), in mice without rod and cone function (Lucas et al., 2001), and in macaques with synaptic blockade of rod-cone responses (Gamlin et al., 2007).

The onset of pupillary light constriction was abnormally slow in the blind patient, suggesting that rods/cones mediate the initial rapid pupillary response to light in sighted individuals. After the light stimulus was extinguished, the rate of pupillary dilation was also unusually slow in the blind patient, even though postillumination pupillary constriction is thought to be driven primarily by melanopsin (Gamlin et al., 2007; Kankipati et al., 2010). Our findings are consistent, however, with recent reports demonstrating that patients with outer retinal degeneration show abnormally slow redilation of the pupils following exposure to blue light (Markwell et al., 2010; Kardon et al., 2011; Léon et al., 2012), suggesting a possible role for rod-cone signaling in determining the rate of pupillary redilation after light offset.

The blind individual's pupil was unable to track intermittent light. Instead, pupil diameter decreased in size over the first minute until reaching a stable size, thereafter behaving as if his eyes were being exposed to continuous light. By comparison, in sighted participants, pupillary constriction and dilation responses were closely time-locked to the intermittent light stimulus. Our results are similar to light responses measured from melanopsin cells in rat using a flickering $0.33 \mathrm{~Hz}$ stimulus ( 1 s on, $2 \mathrm{~s}$ off) (Wong et al., 2007). With intact rod-cone signaling, each light pulse elicits a fast depolarization event, whereas during synaptic blockade only the sustained melanopsin-dependent depolarization remains. These findings suggest that visual photoreceptors are required for melanopsin cells to encode fast modulations of light intensity.

Pupil diameter was previously thought to reach a steady-state size within a few minutes of exposure to continuous light (Mure et al., 2009). By using longer-duration exposures, we show that pupil diameter increases monotonically in sighted participants for at least $30 \mathrm{~min}$. As the rate of pupillary escape is log-linear over time (i.e., higher near the beginning of the light stimulus), pupillary responses could appear to reach a steady state when viewed on shorter timescales. Since we provided full-field illumination of both retinas, it is possible that part of the decrease in pupillary constriction early in the light exposure was due to reduction of retinal illumination caused by the PLR itself. The time course of pupillary escape that we observed during the first $5 \mathrm{~min}$ of exposure to light was similar, however, to that described in a study that examined the consensual light reflex, in which the pupil of the stimulated eye was dilated using a mydriatic agent (Mure et al., 2009). Although we chose a stimulus that would not be expected to drive the intrinsic melanopsin cell response $(543 \mathrm{~nm}, 12 \mathrm{log}$ photons $\mathrm{cm}^{-2} \mathrm{~s}^{-1}$ ), we cannot exclude the possibility that melanopsin contributed to the weak sustained response to green light in sighted individuals. Similarly, these experiments do not distinguish between contributions from rods versus cones, as rod photoreceptors can signal nonvisual light responses at photopic intensities (Altimus et al., 2010).

With intermittent light in the $0.1-4 \mathrm{~Hz}$ range, we prevented pupillary escape and enhanced pupillary constriction for at least $30 \mathrm{~min}$, similar to findings for exposure to shorter-duration sinusoidal light (Varjú, 1964; Troelstra, 1968; Clarke et al., 2003). 
Our findings are analogous to the Brucke-Bartley effect (i.e., brightness enhancement) for vision, in which a flickering light stimulus appears brighter than the same light presented continuously, but only within a specific frequency range (Bartley, 1939). The spectral sensitivity of brightness enhancement matches the photopic luminosity function (Walters and Harwerth, 1978), suggesting involvement of cone photoreceptors. We hypothesize that short intermittent dark pulses allow cone photoreceptors the opportunity to dark adapt before each light pulse, thus preventing pupillary escape.

Similar to our findings for the PLR, exposure to intermittent red light enhances circadian phase shift responses in Opn1mw ${ }^{R}$ mice that express human long-wavelength sensitive opsin (Lall et al., 2010). Together, these results raise the possibility that nonvisual light responses in humans can be driven, and perhaps enhanced, by intermittent light therapy that targets activation of cone photoreceptors. Since circadian and pupillary light responses are driven by different populations of melanopsin cells in mice (Chen et al., 2011), additional studies are required to determine whether our findings for the PLR are generalizable to other nonvisual light responses in humans.

Although we did not study age-matched controls, pupillary light responses in the blind individual (aged 58 years) were many times slower than predicted for a normally sighted individual in the same age group (Feinberg and Podolak, 1965; Alexandridis and Manner, 1977; Pfeifer et al., 1983; Straub et al., 1992; Bitsios et al., 1996). To account for age-dependent differences, we normalized PLR responses to dark-adapted pupil size (i.e., we determined percentage pupillary constriction, which is stable across age groups) (Birren et al., 1950; Daneault et al., 2012). In doing so, we found that the sensitivity of pupillary responses in the blind individual was similar to mice without rod-cone function (Lucas et al., 2003; Do et al., 2009) and macaques with pharmacologic blockade of synaptic input to ipRGCs (Gamlin et al., 2007); hence we consider it unlikely that age-related decline in sympathetic or retinal function contributed substantially to differences we observed in pupillary responses between sighted individuals and the older blind patient.

Our findings have potential implications for how rod/cone and melanopsin dysfunction is assessed in patient populations (Kankipati et al., 2010, 2011; Kawasaki et al., 2010; Kardon et al., 2011). Here, we characterized PLR responses in a blind patient who was previously described as having pupils that were unresponsive to light based on a standard penlight examination performed by an ophthalmologist (Zaidi et al., 2007). Based on our findings, clinical testing of pupillary light responses in patients with visual loss should be performed in darkness, using longerduration light stimuli in addition to short light pulses. Our results may explain why, in a previous study, totally visually blind individuals with intact circadian responses failed to show a PLR during a routine ophthalmologic exam (Czeisler et al., 1995). Pupillary light responses could potentially be used to screen for blind patients with intact circadian photoreception who should continue to expose themselves to light-dark cues to entrain to the $24 \mathrm{~h}$ solar day. This test might be particularly important in visually impaired patients considering enucleation, to avoid removing a light-sensitive eye. Hence, in future studies it will be important to examine the relationship between pupillary light constriction and other nonvisual light responses in patients with visual dysfunction.

\section{References}

Alexandridis E, Koeppe ER (1969) The spectral sensitivity of retinal photoreceptors conducting the pupillary light reflex in humans (in German). Albrecht Von Graefes Arch Klin Exp Ophthalmol 177:136-151.

Alexandridis E, Manner M (1977) Frequency of the pupillary response following flicker stimuli (in German). Albrecht Von Graefes Arch Klin Exp Ophthalmol 202:175-180.

Alpern M, Campbell FW (1962) The spectral sensitivity of the consensual light reflex. J Physiol 164:478-507.

Altimus CM, Güler AD, Alam NM, Arman AC, Prusky GT, Sampath AP, Hattar S (2010) Rod photoreceptors drive circadian photoentrainment across a wide range of light intensities. Nat Neurosci 13:1107-1112.

Bartley SH (1939) Some effects of intermittent photic stimulation. J Exp Psychol 25:462-480.

Belenky MA, Smeraski CA, Provencio I, Sollars PJ, Pickard GE (2003) Melanopsin retinal ganglion cells receive bipolar and amacrine cell synapses. J Comp Neurol 460:380-393.

Berson DM, Dunn FA, Takao M (2002) Phototransduction by retinal ganglion cells that set the circadian clock. Science 295:1070-1073.

Birren JE, Casperson RC, Botwinick J (1950) Age changes in pupil size. J Gerontol 5:216-221.

Bitsios P, Prettyman R, Szabadi E (1996) Changes in autonomic function with age: a study of pupillary kinetics in healthy young and old people. Age Ageing 25:432-438.

Bouma H (1962) Size of the static pupil as a function of wavelength and luminosity of the light incident on the human eye. Nature 193:690-691.

Brainard GC, Rollag MD, Hanifin JP (1997) Photic regulation of melatonin in humans: ocular and neural signal transduction. J Biol Rhythms 12:537-546.

Brainard GC, Hanifin JP, Greeson JM, Byrne B, Glickman G, Gerner E, Rollag MD (2001) Action spectrum for melatonin regulation in humans: evidence for a novel circadian photoreceptor. J Neurosci 21:6405-6412.

Campbell FW, Gregory AH (1960) Effect of size of pupil on visual acuity. Nature 187:1121-1123.

Chen SK, Badea TC, Hattar S (2011) Photoentrainment and pupillary light reflex are mediated by distinct populations of ipRGCs. Nature 476:92-95.

Clarke RJ, Zhang H, Gamlin PD (2003) Characteristics of the pupillary light reflex in the alert rhesus monkey. J Neurophysiol 89:3179-3189.

Czeisler CA, Shanahan TL, Klerman EB, Martens H, Brotman DJ, Emens JS, Klein T, Rizzo JF 3rd (1995) Suppression of melatonin secretion in some blind patients by exposure to bright light. N Engl J Med 332:6-11.

Dacey DM, Liao HW, Peterson BB, Robinson FR, Smith VC, Pokorny J, Yau KW, Gamlin PD (2005) Melanopsin-expressing ganglion cells in primate retina signal colour and irradiance and project to the LGN. Nature 433:749-754.

Daneault V, Vandewalle G, Hébert M, Teikari P, Mure LS, Doyon J, Gronfier C, Cooper HM, Dumont M, Carrier J (2012) Does pupil constriction under blue and green monochromatic light exposure change with age? J Biol Rhythms 27:257-264.

Do MT, Kang SH, Xue T, Zhong H, Liao HW, Bergles DE, Yau KW (2009) Photon capture and signalling by melanopsin retinal ganglion cells. Nature 457:281-287

Feinberg R, Podolak E (1965) Latency of pupillary reflex to light stimulation and its relationship to aging. In: Behavior, aging and the nervous system (Welford AT, Birren JE, eds), pp 1-14. Springfield, IL: Charles C. Thomas.

Gamlin PD, McDougal DH, Pokorny J, Smith VC, Yau KW, Dacey DM (2007) Human and macaque pupil responses driven by melanopsincontaining retinal ganglion cells. Vision Res 47:946-954.

Gooley JJ, Lu J, Fischer D, Saper CB (2003) A broad role for melanopsin in nonvisual photoreception. J Neurosci 23:7093-7106.

Gooley JJ, Rajaratnam SM, Brainard GC, Kronauer RE, Czeisler CA, Lockley SW (2010) Spectral responses of the human circadian system depend on the irradiance and duration of exposure to light. Sci Transl Med 2:31 ra33.

Grozdanic SD, Matic M, Sakaguchi DS, Kardon RH (2007) Evaluation of retinal status using chromatic pupil light reflex activity in healthy and diseased canine eyes. Invest Ophthalmol Vis Sci 48:5178-5183.

Güler AD, Ecker JL, Lall GS, Haq S, Altimus CM, Liao HW, Barnard AR, Cahill H, Badea TC, Zhao H, Hankins MW, Berson DM, Lucas RJ, Yau KW, Hattar S (2008) Melanopsin cells are the principal conduits for rod-cone input to non-image-forming vision. Nature 453:102-105.

Hattar S, Liao HW, Takao M, Berson DM, Yau KW (2002) Melanopsin- 
containing retinal ganglion cells: architecture, projections, and intrinsic photosensitivity. Science 295:1065-1070.

Hattar S, Lucas RJ, Mrosovsky N, Thompson S, Douglas RH, Hankins MW, Lem J, Biel M, Hofmann F, Foster RG, Yau KW (2003) Melanopsin and rod-cone photoreceptive systems account for all major accessory visual functions in mice. Nature 424:76-81.

Kankipati L, Girkin CA, Gamlin PD (2010) Post-illumination pupil response in subjects without ocular disease. Invest Ophthalmol Vis Sci 51:2764-2769.

Kankipati L, Girkin CA, Gamlin PD (2011) The post-illumination pupil response is reduced in glaucoma patients. Invest Ophthalmol Vis Sci 52:2287-2292.

Kardon R, Anderson SC, Damarjian TG, Grace EM, Stone E, Kawasaki A (2011) Chromatic pupillometry in patients with retinitis pigmentosa. Ophthalmology 118:376-381.

Kawasaki A, Herbst K, Sander B, Milea D (2010) Selective wavelength pupillometry in Leber hereditary optic neuropathy. Clin Experiment Ophthalmol 38:322-324.

Kessel L, Lundeman JH, Herbst K, Andersen TV, Larsen M (2010) Agerelated changes in the transmission properties of the human lens and their relevance to circadian entrainment. J Cataract Refract Surg 36:308-312.

Klerman EB, Shanahan TL, Brotman DJ, Rimmer DW, Emens JS, Rizzo JF 3rd, Czeisler CA (2002) Photic resetting of the human circadian pacemaker in the absence of conscious vision. J Biol Rhythms 17:548-555.

Lall GS, Revell VL, Momiji H, Al Enezi J, Altimus CM, Güler AD, Aguilar C, Cameron MA, Allender S, Hankins MW, Lucas RJ (2010) Distinct contributions of rod, cone, and melanopsin photoreceptors to encoding irradiance. Neuron 66:417-428.

Léon L, Crippa SV, Borruat FX, Kawasaki A (2012) Differential effect of long versus short wavelength light exposure on pupillary re-dilation in patients with outer retinal disease. Clin Experiment Ophthalmol 40:e16-e24.

Lucas RJ, Douglas RH, Foster RG (2001) Characterization of an ocular photopigment capable of driving pupillary constriction in mice. Nat Neurosci 4:621-626.

Lucas RJ, Hattar S, Takao M, Berson DM, Foster RG, Yau KW (2003) Diminished pupillary light reflex at high irradiance in melanopsin-knockout mice. Science 299:245-247.

Markwell EL, Feigl B, Zele AJ (2010) Intrinsically photosensitive melanopsin retinal ganglion cell contributions to the pupillary light reflex and circadian rhythm. Clin Exp Optom 93:137-149.
McDougal DH, Gamlin PD (2010) The influence of intrinsicallyphotosensitive retinal ganglion cells on the spectral sensitivity and response dynamics of the human pupillary light reflex. Vision Res 50:72-87.

Motulsky H, Christopoulos A (2008) Fitting models to biological data using linear and nonlinear regression: a practical guide to curve fitting. New York: Oxford UP.

Mure LS, Cornut PL, Rieux C, Drouyer E, Denis P, Gronfier C, Cooper HM (2009) Melanopsin bistability: a fly's eye technology in the human retina. PLoS One 4:e5991.

Panda S, Provencio I, Tu DC, Pires SS, Rollag MD, Castrucci AM, Pletcher MT, Sato TK, Wiltshire T, Andahazy M, Kay SA, Van Gelder RN, Hogenesch JB (2003) Melanopsin is required for non-image-forming photic responses in blind mice. Science 301:525-527.

Pfeifer MA, Weinberg CR, Cook D, Best JD, Reenan A, Halter JB (1983) Differential changes of autonomic nervous system function with age in man. Am J Med 75:249-258.

Rushton WA (1963) Cone pigment kinetics in the protanope. J Physiol 168:374-388.

Straub RH, Thies U, Kerp L (1992) The pupillary light reflex. 1. Agedependent and age-independent parameters in normal subjects. Ophthalmologica 204:134-142.

Troelstra A (1968) Detection of time-varying light signals as measured by the pupillary response. J Opt Soc Am 58:685-690.

Tsujimura S, Ukai K, Ohama D, Nuruki A, Yunokuchi K (2010) Contribution of human melanopsin retinal ganglion cells to steady-state pupil responses. Proc Biol Sci 277:2485-2492.

Varjú D (1964) The influence of sinusoidal luminous density changes on the mean pupil width and on subjective brightness. Kybernetik 2:33-43.

Viénot F, Bailacq S, Rohellec JL (2010) The effect of controlled photopigment excitations on pupil aperture. Ophthalmic Physiol Opt 30:484-491.

Walters JW, Harwerth RS (1978) The mechanism of brightness enhancement. Vision Res 18:777-779.

Wong KY, Dunn FA, Graham DM, Berson DM (2007) Synaptic influences on rat ganglion-cell photoreceptors. J Physiol 582:279-296.

Zaidi FH, Hull JT, Peirson SN, Wulff K, Aeschbach D, Gooley JJ, Brainard GC, Gregory-Evans K, Rizzo JF 3rd, Czeisler CA, Foster RG, Moseley MJ, Lockley SW (2007) Short-wavelength light sensitivity of circadian, pupillary, and visual awareness in humans lacking an outer retina. Curr Biol 17:2122-2128. 